\title{
Evaluation of Biomarkers in Myoma Patients: A Prospective Study Investigating the Role of LDH, CA 125, and IGF-1 after Uterus-Preserving Surgical Therapy
}

\author{
Michaela Jacob Rolf Richter Jalid Sehouli Matthias David \\ Department of Gynecology with Center for Oncological Surgery, Campus Virchow Charité University Hospital Berlin, \\ Berlin, Germany
}

\section{Keywords}

Myomas · Uterine fibroids · Biomarker · Lactate

dehydrogenase $\cdot$ Insulin-like growth factor 1

\begin{abstract}
Objective: Myomas are one of the most common tumors of the lower abdomen in women. At present, sonography and clinical examination are the prevalent diagnostic standards for these tumors, and no biomarkers have been established yet. The primary aim of this study was to determine if the surgical removal of myomas leads to a drop of lactate dehydrogenase (LDH), CA 125, and/or insulin-like growth factor (IGF-1) and therefore if these parameters are suitable as potential biomarkers for the presence or recurrence of a myoma. Study Design: The blood levels of LDH, CA 125, and IGF1 were determined in 83 patients (age 18-50) with a verified diagnosis of myomas and surgical therapy at 3 different timepoints: preoperative (T0), 2 days postoperative (T1), and 6 months postoperative (T2). Vaginal sonography was performed preoperatively and once again at 6 months postoperatively. Results: The median (Q1-Q3) LDH values dropped significantly postoperatively: 239 (217-266) U/L at T0 versus 217 (190-255) U/L at T1, $p<0.001$. The median (Q1-Q3) IGF1 values also dropped: $140.4(118.6-179.0) \mathrm{ng} / \mathrm{mL}$ versus 112.4 (99.5-143.0), $p<0.001$. By contrast, the CA 125 values
\end{abstract}

karger@karger.com www.karger.com/goi

Karger $\frac{1}{\%}$

GOPEN ACCESS
(C) 2021 The Author(s)

Published by S. Karger AG, Basel

This is an Open Access article licensed under the Creative Commons Attribution-NonCommercial-4.0 International License (CC BY-NC) (http://www.karger.com/Services/OpenAccessLicense), applicable to the online version of the article only. Usage and distribution for commercial purposes requires written permission. rose slightly but not significantly. At 6 months $(n=34)$, the $\mathrm{LDH}$ values were not significantly different from either the preoperative or the immediate postoperative values. This was observed both in patients with and without a recurrence of myoma. In contrast, the median (Q1-Q3) IGF-1 level at T2 was significantly elevated both in patients with sonographic evidence of new myomas (129.0 [116.0-163.1] $\mathrm{ng} / \mathrm{mL}, p=$ 0.023 ) and in patients with sonographic proof of no new myomas (161.0 [130.2-198.5] ng/mL, $p<0.001)$. Conclusion: Both LDH and IGF-1 dropped significantly in the immediate postoperative days in women with myomas after uterus-preserving surgeries were performed. The postoperative concentration of IGF-1 was correlated with the evidence of new myomas and can be potentially used for further monitoring. Future studies should be able to confirm these results. This study concludes that myomas do influence LDH and IGF-1 and could possibly be suitable as biomarkers.

(C) 2021 The Author(s).

Published by S. Karger AG, Basel

\section{Introduction}

Myomas are the most frequent benign tumors of the uterus and affect $40-60 \%$ of women of reproductive age; the incidence rises with age [1]. They consist of monoclonal smooth muscle cells of the myometrium [2]. About 
$20 \%$ of myomas become symptomatic and thereby constrict the patients' quality of life [3, 4]. Sonography and clinical examination are the current diagnostic standards [5]. In general, biomarkers can be used in various clinically routine situations, for the screening of subclinical illnesses, risk stratification, checking progress, monitoring, therapy, or preoperative planning $[6,7]$. So far there has been no established biomarker for myomas, yet there are results from some studies in which various enzymes or growth factors were investigated as possible biomarkers for myomas [8].

Lactate dehydrogenase (LDH), an enzyme of anaerobic glycolysis, is often elevated in cancer. Koukourakis et al. [9] found significantly elevated values of LDHA in 24 patients with myomas in comparison to a control group without myomas.

The tumor marker CA 125 is mostly used as a tumor marker for serous ovarian carcinoma, but elevated levels are also found in breast cancer and other malignancies, in benign gynecological diseases such as endometriosis or ovarian cysts, in early pregnancy, and also in general diseases such as renal insufficiency and hepatitis [10-14]. The level of CA 125 has been investigated for myomas in various studies with partially contradictory results [8]. While Dingiloglu et al. [15] and Dawood and Khan-Dawood [16] found CA 125 levels were not elevated in 38 myoma patients and 51 myoma patients, respectively, Tsao et al. [17] and other studies showed elevated CA 125 levels in patients with myomas [18].

Insulin-like growth factor 1 (IGF-1) might play an important role in the growth of myomas [19]. There are contradictory results also for the level of IGF-1 in myoma patients. In the study by Dawood and Khan-Dawood [16], no difference was found between patients with myomas and the myoma-free control group. Baird et al. [20] rejected the hypothesis that high levels of circulating IGF-1 might be associated with increased myoma prevalence. Whereas $\mathrm{Mu}$ et al. [21] reported significantly elevated IGF-1 values in a group of 70 myoma patients in comparison to control groups without myomas and likewise a significant drop of the IGF-1 level after myoma therapy by means of uterine artery embolization (UAE).

The aim of this prospective study was to investigate whether the surgical removal of myomas leads to a decrease of the potential myoma biomarkers of LDH, CA 125 , and IGF-1. The following 4 secondary study questions were also answered. (1) Do the values of the biomarkers correlate primarily with the size or the location of the myomas or the severity of symptoms? (2) Does a drop in a single or multiple biomarkers occur immediately postoperatively after myoma removal? (3) Does the recurrence of myomas 6 months postoperatively, which can be demonstrated by means of ultrasound, correlate with a resurgence of individual biomarkers? (4) Can a cutoff value be defined, and if so which biomarker or biomarkers should be viewed as predictive values for the recurrence of myomas? Or can individual or multiple values of the biomarkers in combination with other parameters provide information on the occurrence of myomas? (5) Are the serum values of LDH higher when sonographic or histopathological signs of degeneration/necrosis of myomas are present?

\section{Materials and Methods}

\section{Ethics}

The Ethics Commission approved this study. All patients provided written informed consent. The regulations of the Berlin Data Protection Law and the guidelines for "Good Scientific Practice" of Charité were followed.

\section{Study Sample}

In a prospective study of the Department of Gynecology and Obstetrics of the Charité University Hospital in Berlin, LDH, CA 125, and IGF-1 were investigated as possible biomarkers for the existence or recurrence of myomas. Statistical planning of the sample size on the basis of results from $\mathrm{Mu}$ et al. [21] yielded a necessary sample size of $n=83$ patients. The inclusion criteria were patients with at least one sonographically demonstrable myoma and who needed uterus-preserving surgical therapy. Patients with no postoperative histological confirmation of the myoma were retroactively excluded. Further exclusion criteria were age $<18$ or $>50$, patients in menopause, patients lacking the capacity to provide consent, or patients with a hysterectomy. Enrollment took place from June 2016 until August 2018.

\section{Data Collection}

LDH, CA 125, and IGF-1 levels in the venous blood were determined in the participating patients at 3 different time points: preoperative (T0) (during the consultation hours for planning the operation, a few days to weeks before the operation), 2 days postoperative (T1), and 6 months postoperative (T2). The patients were not fasting at any of these time points. Vaginal sonography was performed preoperatively and at 6 months postoperatively by the same investigator (MD). Furthermore, the patients' medical records were evaluated for the dates of myoma-related symptoms, relevant secondary diagnoses, and characteristics of the myomas (routine questionnaire for all patients).

The fresh blood samples were all analyzed at the Berlin Laboratory. Photometric determination according to the ICFF procedure was used to determine the LDH value; electrochemiluminescence immunoassay was used to determine the CA 125 value; and chemiluminescence assay was used to determine the IGF-1 value. The threshold values were defined according to the standards of the 


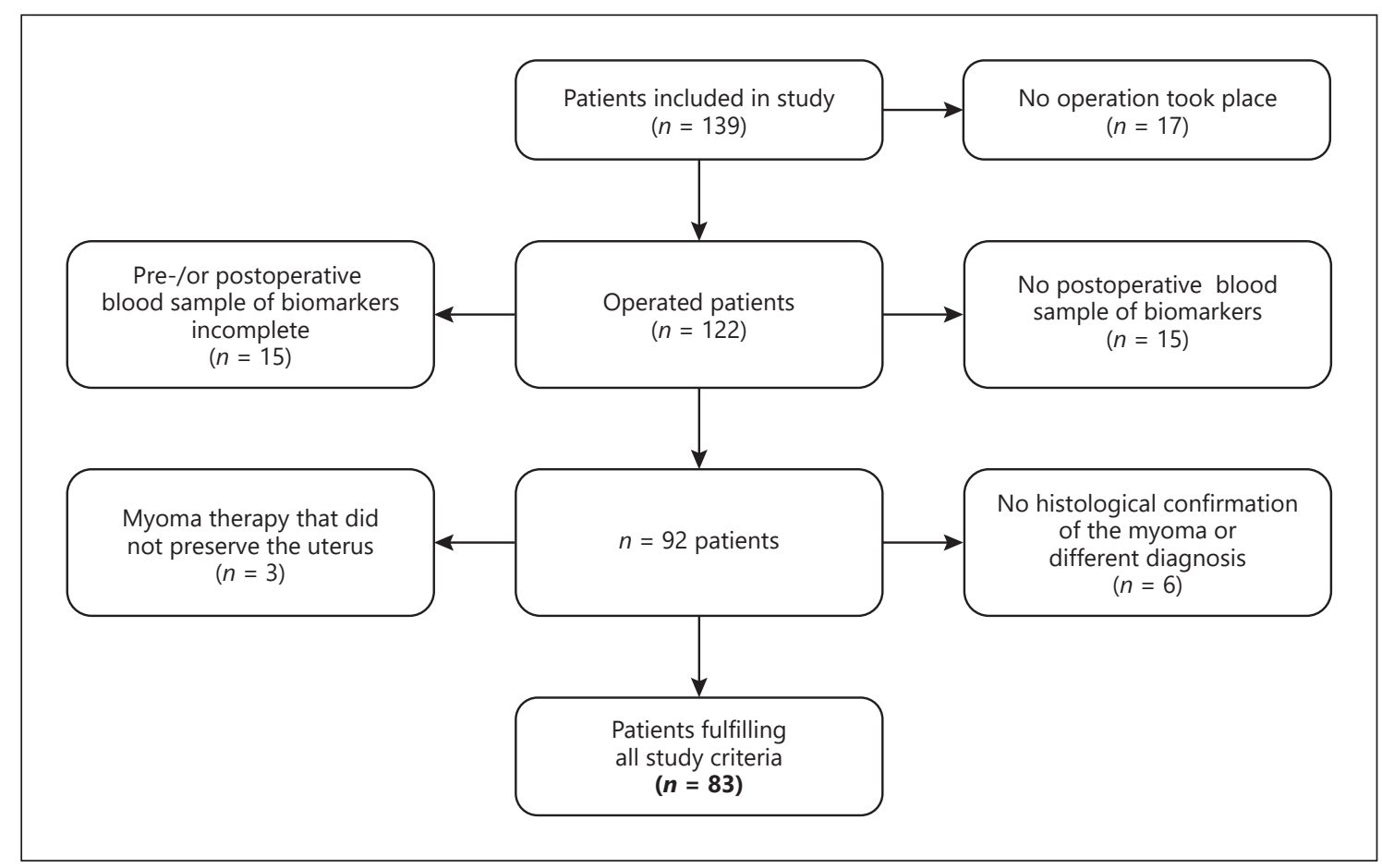

Fig. 1. Exclusions after enrollment.

Berlin Laboratory as follows: LDH: 135-250 U/L; CA 125: <35 $\mathrm{kU} / \mathrm{L}$; IGF-1: age-adapted reference ranges for women of 119.5$496.9 \mathrm{ng} / \mathrm{mL}$ for 18 -year-olds down to $59.7-202.3 \mathrm{ng} / \mathrm{mL}$ for 50 -year-olds. The IDS-iSYS IGF-I assay was used. The assay is based on chemiluminescence technology. The following values apply with regard to sensitivity: limit of blank $=1.9 \mathrm{ng} / \mathrm{mL}$; limit of detection $=4.4 \mathrm{ng} / \mathrm{mL}$; limit of quantitation $=8.8 \mathrm{ng} / \mathrm{mL}$.

\section{Statistical Analysis}

SPSS (IBM Corp. Released 2015, IBM SPSS Statistics for Windows, Version 23.0; IBM Corp., Armonk, NY, USA) was used for the statistical evaluation of the data. A $p$ value $<0.05$ was considered significant. The normal distribution of the data was checked with the Kolmogorov-Smirnov test. Since there was no normal distribution, the further evaluation was done with nonparametric tests. The results of the biomarkers and other continuous variables were summarized as the median and interquartile range. For each of the 3 potential biomarkers, the Wilcoxon test for paired samples was used to compare the values at $\mathrm{T} 0$ versus $\mathrm{T} 1$ and at $\mathrm{T} 1$ versus T2. Spearman's correlation coefficient was used to test the correlation between the levels of the blood values of LDH, CA 125, and IGF-1 and the various parameters of the myomas, such as size, weight, number, and location, as well as the intensity of symptoms. Various models of the influence of the biomarkers on the presence or recurrence of myomas at different time points were tested by means of logistic regression. Due to the small number of cases at time point T2, variables were entered into the model for the recurrence of myomas at $p<0.15$.

\section{Results}

A total of 139 patients were included in the study, of whom 83 fulfilled all study criteria. The exact dropout process is presented in Figure 1, and the flow of the study cohort through the 3 study time points is presented in Figure 2. The median (Q1-Q3) age of the 83 patients at study enrollment was 38 years (35-42.5).

Laparotomy was performed on 53 patients, laparoscopy on 13 , and hysteroscopy on 16 , whereby only a partial removal of the myoma was possible for 10 patients who had a type II myoma. One patient received a combined operation (laparoscopy and hysteroscopy). UAE was performed preoperatively in preparation for the laparotomy in 4 patients. The number, sizes, and locations of the removed myomas are presented in Table 1.

The median (Q1-Q3) LDH value at T0 was 239.0 (217.0266.0) U/L. Thereby, 31 of the 83 patients (37.3\%) had an elevated LDH value, and the median was only barely below the upper cutoff value of $250 \mathrm{U} / \mathrm{L}$. The median (Q1-Q3) CA 125 value at T0 was $17.0(11.7-24.0) \mathrm{kU} / \mathrm{L}$. Eleven (13.3\%) of the patients were above the reference value of $35 \mathrm{kU} / \mathrm{L}$. The median (Q1-Q3) value of IGF-1 at T0 was 140.4 (118.6-179.0) ng/mL. The cutoff values for IGF-1 are graduated according to age, whereby they decrease with increas- 


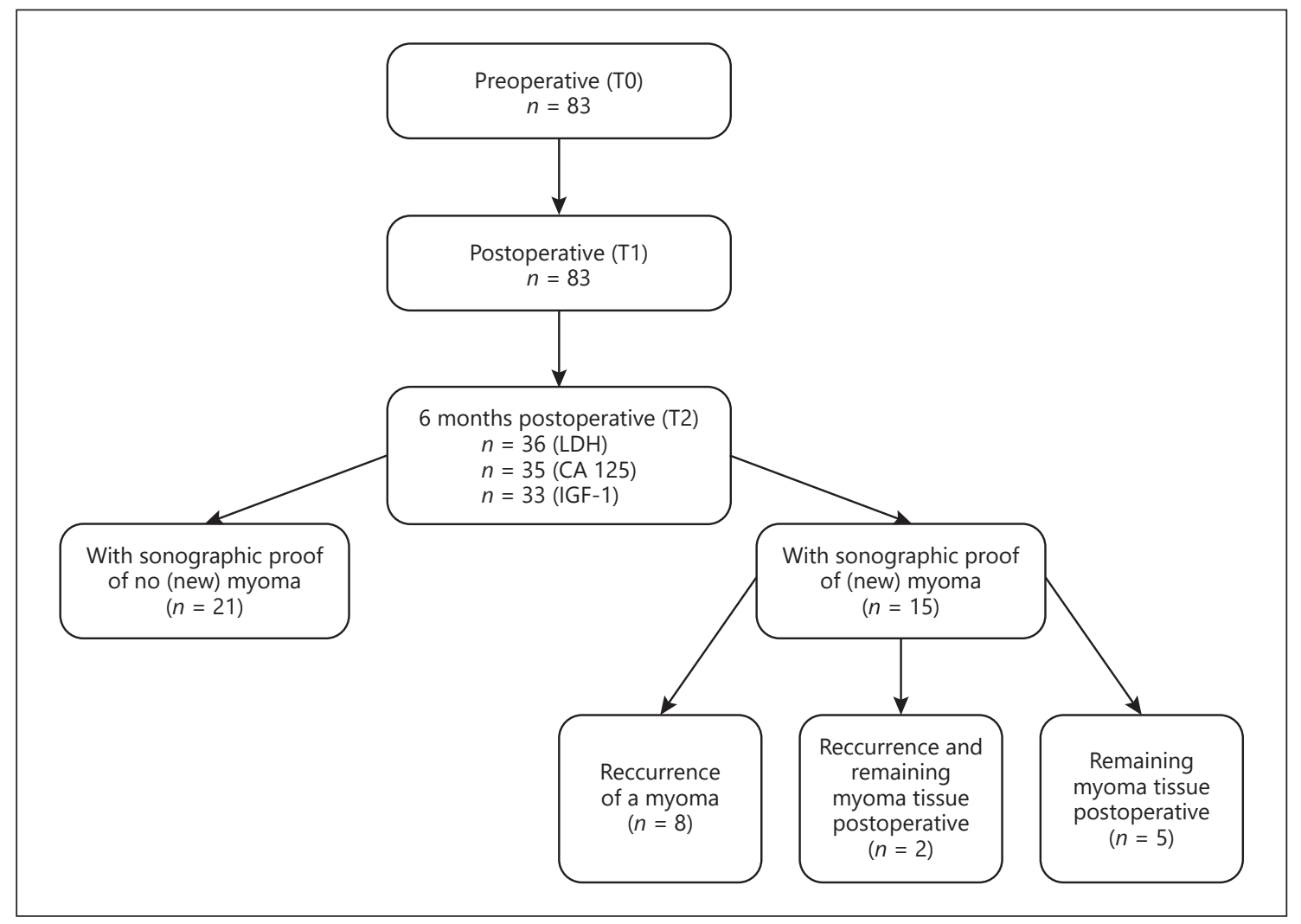

Fig. 2. Study sample at the 3 measurement time points. LDH, lactate dehydrogenase; IGF-1, insulin-like growth factor 1

Table 1. Characteristics of the myomas

\begin{tabular}{lcc}
\hline & Characteristics & $\begin{array}{l}\text { Number of } \\
\text { patients }\end{array}$ \\
\hline Number of myomas, mean \pm SD (range) & $2.2 \pm 2.3(1-15)$ & $n=83$ \\
$1, n(\%)$ & $48(57)$ & $23(33.7)$ \\
$2-4, n(\%)$ & $4(4.8)$ & $n=79$ \\
$5-7, n(\%)$ & $3(3.6)$ & $n=47$ \\
$\geq 8, n(\%)$ & $7.5 \pm 4.3(1.4-19.6)$ & $n=83$ \\
Size (largest diameter), cm, mean \pm SD (range) & $206.3 \pm 213.5(7-920)$ & \\
Weight (total weight of all removed myomas), g, mean \pm SD (range) & & $n=83$ \\
Location, $n(\%)$ & $16(19.3)$ & $33(39.8)$ \\
$\quad$ FIGO 0, 1,2 & $9(10.8)$ & $25(30.1)$ \\
$\quad$ FIGO 3, 4 & $38(45.8)$ & \\
$\quad$ FIGO 5, 6, 7 & & \\
Several fibroids with different localizations & & \\
Regressive changes present, $n$ (\%) & & \\
\hline
\end{tabular}




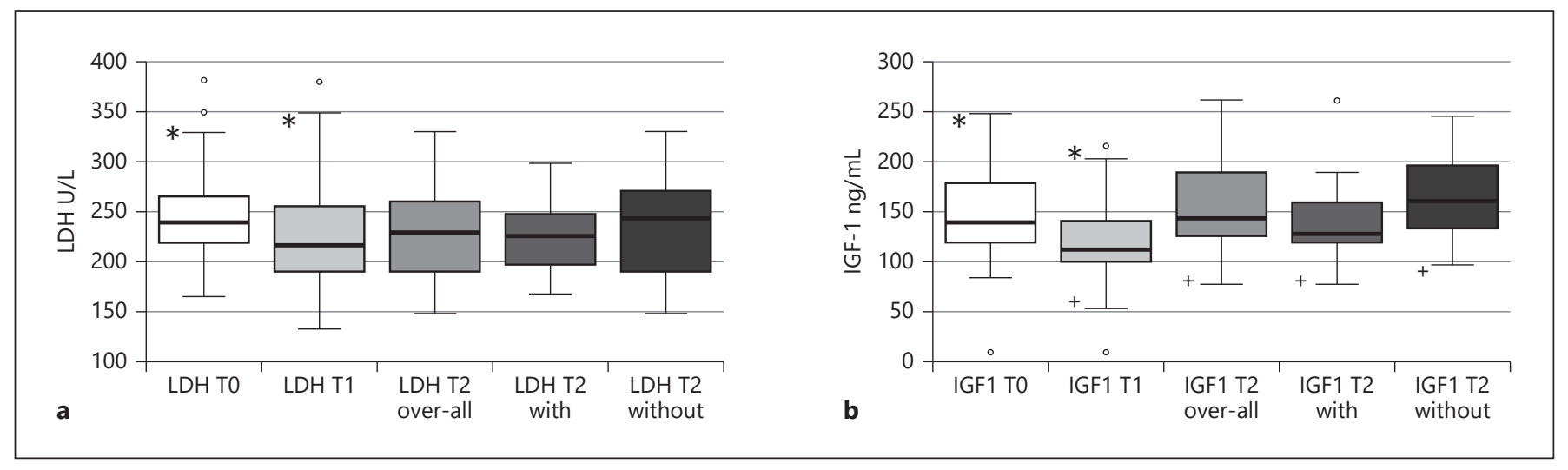

Fig. 3. a Level of the LDH blood values at the 3 measurement time points. b Level of the IGF-1 blood values at the 3 measurement time points. *Significant difference between T0 and T1. ${ }^{+}$Significant difference between T1 and T2 and also for both subgroups at T2. LDH, lactate dehydrogenase; IGF-1, insulin-like growth factor 1.

ing age. Only 5 patients (6\%) had a preoperative IGF-1 level above the age-dependent cutoff levels.

Postoperatively, the median (Q1-Q3) LDH values decreased significantly: $239.0(217.0-266.0) \mathrm{U} / \mathrm{L}$ at T0 versus 217 (190.0-255.0) U/L, $p<0.001$ (shown in Fig. 3a). The median (Q1-Q3) IGF-1 values behaved similarly: $140.4(118.6-179.0) \mathrm{ng} / \mathrm{mL}$ at $\mathrm{T} 0$ versus $112.4(99.5-$ 143.0) ng/mL, $p<0.001$ (shown in Fig. 3b). By contrast, the CA 125 values rose slightly to T1, but not significantly. Nonetheless, the median (Q1-Q3) values dropped significantly from T1 to T2: $14.3(9.8-18.6) \mathrm{kU} / \mathrm{L}$ at T2, $p=$ 0.006 , and in the subgroup with recurrent or remaining myoma tissue at T2: $15.6(10.0-24.2) \mathrm{kU} / \mathrm{L}$ at T2, $p=$ 0.041 . The values for LDH after 6 months showed no significant difference to the values established at the immediate postoperative time point. This was the case both for patients with and without recurrence of a myoma (shown in Fig. 3a). By contrast, the median (Q1-Q3) values of IGF-1 were significantly elevated at T2 compared to T1, also for both subgroups: $144.9(124.7-191.2) \mathrm{ng} / \mathrm{mL}$ at $\mathrm{T} 2, p<0.001 ; 129.0(116.0-163.1) \mathrm{ng} / \mathrm{mL}$ at $\mathrm{T} 2$ for $\mathrm{pa}-$ tients with recurrence, $p=0.023 ; 161.0(130.2-198.5) \mathrm{ng} /$ $\mathrm{mL}$ at $\mathrm{T} 2$ for patients without recurrence, $p<0.001$ (shown in Fig. 3b). The complete results on the levels of the 3 biomarkers at the 3 time points are shown in Table 2 and the time course of the 3 biomarkers in Figure 4.

A risk score for the preoperative existence of more than one myoma was calculated using the results of stepwise logistic regression ( $\mathrm{pin}=0.05$, pout $=0.10$ ) in 2 blocks, first age and then LDH, CA 125, and IGF-1 grouped according to the results of ROC analysis. This yielded the following risk equation for more than one my-

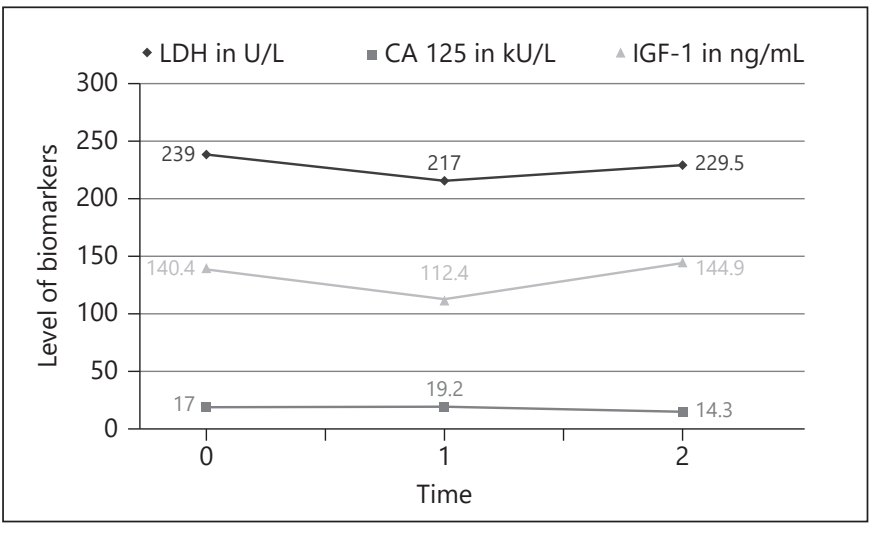

Fig. 4. Changes of LDH, CA 125, and IGF-1 during 3 time points. $\mathrm{LDH}$, lactate dehydrogenase; IGF-1, insulin-like growth factor 1.

oma: $-4.518+(0.07 \times$ age $)+1.362($ if $\mathrm{LDH}>223)+1.010$ (if CA $125>17$ ).

In another stepwise logistic regression model, it was shown that the 3 variables of patient age $>36$, myoma size $>65 \mathrm{~mm}$, and IGF-1 value $>110 \mathrm{ng} / \mathrm{mL}$ at $\mathrm{T} 1$ were relevant risk factors for the recurrence of a myoma but not for the number of myomas or high levels of CA 125 or LDH. Due to the small case number at time point $\mathrm{T} 2$, with only 10 patients with myoma recurrence, variables were taken into the model with $p<0.15$. There was no significant influence of the values of the biomarkers at $\mathrm{T} 2$ on the recurrence of a myoma at 6 months. The calculations for the recurrence of a myoma according to the number of the risk factors (age $>36$, myoma size $>65 \mathrm{~mm}$, and IGF-1 
Table 2. Blood values of the 3 biomarkers at the 3 measurement time points, as median (Q1-Q3)

\begin{tabular}{|c|c|c|c|c|c|c|c|}
\hline & Cases & $\mathrm{LDH}, \mathrm{U} / \mathrm{L}$ & $p$ value & CA $125, \mathrm{kU} / \mathrm{lL}$ & $p$ value & IGF-1, ng/mL & $p$ value \\
\hline Preoperative (T0) & 83 & $239.0(217.0-266.0)$ & & $17.0(11.7-24.0)$ & & $140.4(118.6-179.0)$ & \\
\hline Immediate postoperative (T1) & 83 & $217.0(190.0-255.0)$ & $<0.001$ & $19.2(12.0-25.8)$ & 0.691 & $112.4(99.5-143.0)$ & $<0.001$ \\
\hline $\mathrm{T} 2$ with recurrence or residual myoma & $15 / 14 / 12$ & $129.0(116.0-163.1)$ & 1.0 & $15.6(10.0-24.2)$ & 0.041 & $129.0(116.0-163.1)$ & 0.023 \\
\hline $\mathrm{T} 2$ without recurrence or residual myoma & 21 & $161.0(130.2-198.5)$ & 0.434 & $13.1(9.1-17.7)$ & 0.062 & $161.0(130.2-198.5)$ & $<0.001$ \\
\hline
\end{tabular}

Table 3. Occurrence of recurrence according to the number of risk factors: age $>36$, myoma size $>65 \mathrm{~mm}$, and IGF-1 at T1 $>110 \mathrm{ng} /$ $\mathrm{mL}$

\begin{tabular}{crrrr}
\hline & \multicolumn{2}{c}{ Number of risks } & Total \\
\cline { 2 - 4 } & $0 / 1$ & 2 & 3 & \\
\hline $\begin{array}{l}\text { Myoma recurrence } \\
\text { No }\end{array}$ & & & & \\
$N$ & 14 & 12 & 2 & 28 \\
$\%$ & 100 & 75 & 25 & 73.7 \\
Yes & & & & \\
$N$ & 0 & 4 & 6 & 10 \\
$\%$ & 0 & 25 & 75 & 26.3 \\
Total & 14 & 16 & 8 & 38 \\
$N$ & 100 & 100 & 100 & 100 \\
$\%$ & & & & \\
\hline
\end{tabular}

$>110 \mathrm{ng} / \mathrm{mL}$ at T1) are presented in Table 3 . If there were no risk factors or at most one, then none of the 14 patients had a recurrence, whereas 6 of 8 patients (75\%) who had all 3 risk factors had a recurrence.

No significant correlation could be shown between the levels of the biomarkers on the one hand and the size, position, number, or weight of the myomas, or the symptom intensity on the other. Also, the existence of regressive changes of the myoma in the histopathological examination showed no significant influence on the level of $\mathrm{LDH}$ in this study.

\section{Discussion}

The present study has prospectively investigated 3 potential biomarkers for myomas at 3 different time points. For the measurement of the blood values of LDH and IGF-1, a significant drop from the preoperative (T0) level to the immediate postoperative (T1) level was shown. On comparison of the immediate postoperative (T1) val- ues to the postoperative values after 6 months (T2), there was only a significant resurgence of the IGF- 1 value in the subgroup of patients with sonographic proof of no new myomas. For CA 125, no significant changes of the blood values could be shown between the 3 time points.

The results on IGF-1 are consistent with those of an earlier comparable study by $\mathrm{Mu}$ et al. [21] in which the values of IGF-1 were determined at several time points for 70 patients receiving UAE as therapy for myomas. These studies also showed a significant drop of IGF-1 1 week after therapy and a significant resurgence in the further course (after 1 month and after 3 months). They therefore concluded that the expression of IGF-1 was first repressed through the myoma therapy by means of UAE and then rose up again in the further course. In the present study, the results after 6 months (T2) deviate from those of $\mathrm{Mu}$ et al. [21]. The thesis of the suitability of IGF-1 as a biomarker for myomas is supported by results from immunohistochemical investigations, which showed an elevated expression of IGF-1 and of the IGF-1 receptor in myomas, compared with neighboring myometrium [22, 23]. This is consistent with the results from Peng et al. [24] which demonstrate increased expressions of IGF-1 in a third of 230 cases studied, as well as a positive correlation between IGF-1 values and the size of the myomas. The thesis of an influence of IGF-1 on the growth of myomas is further supported by the results of Wolanska and Bankowski. In this study, an increased amount of IGF-1 was extracted from myomas compared to healthy myometrium [25].

In the present study, elevated preoperative values for LDH were shown, which corresponds with the results of Koukourakis et al. [9]. These authors showed significantly elevated LDH values in a cohort of 24 myoma patients in comparison to a myoma-free control group. The significant, demonstrable postoperative drop of $\mathrm{LDH}$ in the present study also allows one to conclude that there might be a relationship between the presence of myoma tissue and elevated $\mathrm{LDH}$ values. $\mathrm{LDH}$, as a marker of anaerobic metabolism, can be influenced by many pathologies, and 
therefore is rather unsuitable as a biomarker if considered only by itself [8].

There is controversy in the literature about whether CA 125 is suitable as a biomarker for myomas. In the present study, there were only a few patients with elevated preoperative values for CA 125, and there was no significant drop of the values after the surgical removal of the myomas. This result suggests that CA 125 alone is not suited as a biomarker for myomas. That conclusion was also drawn by the authors of 2 small prospective studies with preoperative measurement of CA 125 in patients and control groups $[15,16]$.

In the logistic regression models, a risk score for the preoperative presence of more than one myoma could be calculated from the age of the patient and 2 biomarker values ( $\mathrm{LDH}$ and CA 125). Three variables were shown as relevant risk factors in a model for the probability of recurrence of a myoma: (patient age $>36$, myoma size $>65$ $\mathrm{mm}$, and IGF- 1 value $>110 \mathrm{ng} / \mathrm{mL}$ ).

This study has some limitations. (1) Although the study sample $(n=83)$ is comparable in size to other studies on this topic, the high dropout rate to timepoint T2 limits the explanatory power of these results. (2) This also applies to the regression models that only had small subgroups of patients. (3) Data on the myoma characteristics were also incomplete. (4) There is a lack of data on secondary diseases of patients that can influence the biomarkers. (5) Even if the first blood sample was taken previously in the 4 patients with additional UAE, a possible influence of the UAE on later values cannot be completely ruled out.

This study has some strengths. (1) Three different biomarkers were tested in the same study sample, which makes the results of the various biomarkers more comparable to each other. (2) The blood sampling for all patients took place at 3 standardized time points. (3) The vaginal sonographic exams were all carried out by the same investigator (MD) with the same device. (4) The diagnosis of myomas was histologically confirmed for all patients retained in the study.
In conclusion, a specific biomarker for myomas could spare patients (more invasive) examinations and lead them to therapy earlier. The results of this study allow the hypothesis that myomas influence LDH and IGF-1, which would mean that they are potentially suitable as biomarkers, though manifold influence factors strongly limit the informative value of LDH. The results of the logistic regression models suggest that the development of a risk score from myoma parameters and biomarkers would be possible in a much larger patient sample in order to predict the existence or recurrence of myomas. Therefore, further prospective studies are warranted.

\section{Acknowledgement}

We would like to thank Michael Hanna, PhD, for translating the manuscript from German into English.

\section{Statement of Ethics}

This study complies with the guidelines for human studies and was conducted ethically in accordance with the World Medical Association Declaration of Helsinki.

\section{Conflict of Interest Statement}

The authors have no conflicts of interest to declare.

\section{Funding Sources}

This study had no financial or material support.

\section{Author Contributions}

Conception and design of the study were done by M.D.; acquisition of data was the responsibility of M.J.; analysis and interpretation of data were done by R.R. and M.J.; statistical analysis was performed by R.R.; drafting of the manuscript was done by M.J.; revision of manuscript for important intellectual content was done by J.S. and M.D. All authors read and approved the final manuscript.

References

1 Parker WH. Etiology, symptomatology, and diagnosis of uterine myomas. Fertil Steril. 2007;87(4):725-36.

2 Stewart EA. Uterine fibroids. Lancet. 2001; 357(9252):293-8.

3 Marino JL, Eskenazi B, Warner M, Samuels S, Vercellini P, Gavoni N, et al. Uterine leiomyoma and menstrual cycle characteristics in a population-based cohort study. Hum Reprod. 2004;19(10):2350-5.

4 Borah BJ, Nicholson WK, Bradley L, Stewart EA. The impact of uterine leiomyomas: a national survey of affected women. Am J Obstet Gynecol. 2013;209(4):319-e20. 
5 Goto A, Takeuchi S, Sugimura K, Maruo T. Usefulness of Gd-DTPA contrast-enhanced dynamic MRI and serum determination of LDH and its isozymes in the differential diagnosis of leiomyosarcoma from degenerated leiomyoma of the uterus. Int J Gynecol Cancer. 2002;12(4):354-61.

6 Christenson RH, Duh SH. Methodological and analytic considerations for blood biomarkers. Prog Cardiovasc Dis. 2012;55(1): 25-33.

7 Vodolazkaia A, El-Aalamat Y, Popovic D, Mihalyi A, Bossuyt X, Kyama CM, et al. Evaluation of a panel of 28 biomarkers for the non-invasive diagnosis of endometriosis. Hum Reprod. 2012;27(9):2698-711.

8 Levy G, Hill MJ, Plowden TC, Catherino $\mathrm{WH}$, Armstrong AY. Biomarkers in uterine leiomyoma. Fertil Steril. 2013;99(4):114652.

9 Koukourakis MI, Kontomanolis E, Giatromanolaki A, Sivridis E, Liberis V. Serum and tissue $\mathrm{LDH}$ levels in patients with breast/gynaecological cancer and benign diseases. Gynecol Obstet Invest. 2009; 67(3):162-8.

10 Medeiros LR, Rosa DD, da Rosa MI, Bozzetti MC. Accuracy of CA 125 in the diagnosis of ovarian tumors: a quantitative systematic review. Ireland; 2009 Feb.

11 Jacobs I, Bast RC Jr. The CA 125 tumourassociated antigen: a review of the literature. Hum Reprod. 1989;4(1):1-12.
12 Devarbhavi H, Kaese D, Williams AW, Rakela J, Klee GG, Kamath PS. Cancer antigen 125 in patients with chronic liver disease. Mayo Clin Proc. 2002;77(6):538-41.

13 Takahashi K, Nagata H, Kijima S, Kusakari M, Shirai T, Yoshino K, et al. Clinical usefulness of determination of CA 125 levels in the serum and menstrual blood. Gynecol Obstet Invest. 1988;26(1):63-5.

14 Bilibio JP, Souza CA, Rodini GP, Andreoli CG, Genro VK, de Conto E, et al. Serum prolactin and CA-125 levels as biomarkers of peritoneal endometriosis. Gynecol Obstet Invest. 2014;78(1):45-52.

15 Dingiloglu BS, Gungor T, Ozdal B, Cavkaytar S, Bilge U, Mollamahmutoglu L. Serum leptin levels in women with uterine leiomyomas. Taiwan J Obstet Gynecol. 2007; 46(1):33-7.

16 Dawood MY, Khan-Dawood FS. Plasma insulin-like growth factor-I, CA-125, estrogen, and progesterone in women with leiomyomas. Fertil Steril. 1994;61(4):617-21.

17 Tsao KC, Hong JH, Wu TL, Chang PY, Sun $\mathrm{CF}, \mathrm{Wu}$ JT. Elevation of CA 19-9 and chromogranin A, in addition to CA 125 , are detectable in benign tumors in leiomyomas and endometriosis. J Clin Lab Anal. 2007; 21(3):193-6.

18 Babacan A, Kizilaslan C, Gun I, Muhcu M, Mungen E, Atay V, et al. CA 125 and other tumor markers in uterine leiomyomas and their association with lesion characteristics. Int J Clin Exp Med. 2014;7(4):107883.
19 Blake RE. Leiomyomata uteri: hormonal and molecular determinants of growth. J Natl Med Assoc. 2007;99(10):1170-84.

20 Baird DD, Travlos G, Wilson R, Dunson DB, Hill MC, D'Aloisio AA, et al. Uterine leiomyomata in relation to insulin-like growth factor-I, insulin, and diabetes. Epidemiology. 2009;20(4):604-10.

$21 \mathrm{Mu} \mathrm{Y,} \mathrm{He} \mathrm{J,} \mathrm{Yan} \mathrm{R,} \mathrm{Hu} \mathrm{X,} \mathrm{Liu} \mathrm{H,} \mathrm{Hao} \mathrm{Z.}$ IGF-1 and VEGF can be used as prognostic indicators for patients with uterine fibroids treated with uterine artery embolization. Exp Ther Med. 2016;11(2):645-9.

22 Dixon D, He H, Haseman JK. Immunohistochemical localization of growth factors and their receptors in uterine leiomyomas and matched myometrium. Environ Health Perspect. 2000;108(Suppl 5):795-802.

23 Burroughs KD, Howe SR, Okubo Y, FuchsYoung R, LeRoith D, Walker CL. Dysregulation of IGF-I signaling in uterine leiomyoma. J Endocrinol. 2002;172(1):83-93.

24 Peng L, Wen Y, Han Y, Wei A, Shi G, Mizuguchi $M$, et al. Expression of insulin-like growth factors (IGFs) and IGF signaling: molecular complexity in uterine leiomyomas. Fertil Steril. 2009;91(6):2664-75.

25 Wolanska M, Bankowski E. An accumulation of insulin-like growth factor I (IGF-I) in human myometrium and uterine leiomyomas in various stages of tumour growth. Eur Cytokine Netw. 2004;15(4): 359-63. 